\title{
Feeling Less Than Other People: attainment scores as symbols of children's worth
}

\author{
ELEANORE HARGREAVES
}

\begin{abstract}
This article addresses how an educational purpose of social efficiency, such as the one we have in England, affects each child's school Life-history and the process through which children thereby come to identify themselves. The author considers whether schools could engage in practices that decrease pupils' resignation to a system that controls them, and enhance children's resilience; she also considers their resistance towards being unjustly controlled. She addresses this question by exploring primary schooling's relatively recent practice of grouping children according to their attainment scores on tests of maths and writing. She explores how such grouping may contribute to a perception of children as only as valuable as their test scores. With reference to a particular pupil, Wayne, who describes his school Life-history, the author emphasises how struggling with one high-stakes subject can lead children to a sense of being 'less than other people', even when a child has obvious knowledge and skill in other curriculum areas. She then previews a Leverhulme research project which has recently begun, which narrates and investigates 'Children's Life-histories In Primary Schools' (CLIPS) across five years of school, to identify the role played by attainment labels in children's social and cognitive development.
\end{abstract}

\section{The Process of Constructing Beliefs about Self}

Who or what influences how we come to perceive ourselves? How can every primary school child develop into an adult who feels involved with - rather than ring-fenced away from - all the people in his or her social environment What allows one child to grow up as a saint, another as a tyrant? One significant answer to this question is that other people's responses affect who children become. And those other people may be parents, or adults and peers at school. Bakhtin reminds us, 'Neither meaning nor self is a precondition for 
social interaction; rather, these emerge from and are sustained by conversations occurring between people' (cited by Sampson, 1993, pp. 98-99). These are hopeful words, suggesting that each person has the chance to be valued and play a proactively beneficial role in life. However, to understand how this process works for children at school, it is not enough to focus only on their psychological responses to personal interactions. Aspects of the physical, social and political environment also need to be explored - for example, national or global forces which pressurise schools and affect how the people in schools conceptualise and interrelate with each other. In the 'Learning without Limits' language, national and global policies reflect to greater or lesser extents the pedagogical principles of trust, co-agency and 'the ethic of everyone' (Swann et al, this volume). As Moore points out, many education policies today perpetuate 'free-market capitalist systems and ideologies within curriculum selections that reflect the interests and expertise of dominant classes at the expense of dominated classes' (2015, p. 148). Schiro (2013) has compared this 'social efficiency' purpose with another popular educational purpose, the maintenance of the status quo in terms of handing down bodies of knowledge (the 'scholar academic' purpose).

These two purposes portray the school as a place where children are inducted into existing academic and social hierarchies to which they become resigned and by which they become sorted and controlled. On the other hand, Schiro has suggested that the purpose of schooling could instead be the nurturing of well-rounded, empathetic individuals who develop resilience. Or finally, the purpose may be the cultivation of critical individuals who work to change the existing society for the benefit of everyone, resisting the 'discourse of no alternatives' (Unger, 2011). My question, which I start to consider in this article, is how an educational purpose of social efficiency, such as the one we have in England, affects the course of each child's school Life-history and the process through which children come to identify themselves. I consider whether schools could engage in practices that, through interaction, decrease pupils' resignation to a system that controls them, and enhance children's resilience and their resistance towards being unjustly controlled.

Roald Dahl's story The Twits provides a good example of how forces in the social environment can help foster misplaced beliefs about self. Mr Twit tricked his wife by adding a tiny bit of wood to the bottom of her walking stick each day so that the stick imperceptibly grew taller and taller. Because the change was imperceptible on a daily basis, Mrs Twit came to believe that it was she who had shrunk rather than the stick that had grown. As Mr Twit said, 'There's something wrong ... It's not the stick, it's YOU!' Because of conditions beyond her control, and even beyond her awareness, Mrs Twit came to believe that she was less of a person than she really was. She therefore resigned herself to the fact that she now needed to be painfully 'stretched', and even that would not save her. Dahl describes Mrs Twit's discomfort, and that it was not picked up by those around her: 'Mrs Twit became so frightened that she began to dribble. But Mr Twit ... didn't feel sorry for her at all.' 


\section{A Culture of Measurement Rather Than Inquiry}

A schooling system driven by economic purposes and intent on preserving 'traditional' curriculum content is likely to use measurement as its process of evaluation. Rather than using assessment to investigate and inquire into children's learning, this system uses measurement data to prove its successes, to sort, and to sustain control. Children are measured according to how well they conform to the system's purposes. These are symbolised by tests of maths and writing, the 'core' of the traditional curriculum and the essentials traditionally required by employers. As we saw in England in the 1990s, this encourages schools to define children by their attainment rather than as people with complex, unique Life-histories (see also Reay \& Wiliam, 1999). As attainment is emphasised, children start to define themselves in terms of their school test attainment rather than as people with rich Life-histories. This may make them feel better than other people if their test attainment is high. But if it is low, it may make them feel less than other people. Like Mrs Twit, these latter children may feel anxious or defeated, as they come to perceive themselves as 'less of a person' - despite not knowing how this has happened nor how to change it.

How this happens and how we might change it is the focus of the current article and of our newly funded research project, 'Children's Life-histories In Primary Schools' (CLIPS). This study is a longitudinal inquiry that explores how primary children come to identify themselves over five years within attainment-focused schooling. Below, I first illustrate these issues through a focus on Wayne, now 18 years old, who was frustrated by being labelled 'low ability' throughout his school life. Second, I describe the CLIPS project and how we hope to explore these issues through the school Life-histories of pupils from Year 3 to Year 7.

\section{The Acceptance of Grouping by 'Ability'}

The idea of categorising children according to how well they perform on maths and writing tests, despite being prevalent in secondary schools, was practically unthinkable in primary schools during the late 1970s and 1980s. Many teachers at that time assumed that their job was to orchestrate inclusive classrooms where children of all ethnicities, languages, interests and strengths were equally valued and nurtured. It was common in those days for teachers to place children in different groups within one classroom, but not according to measured attainment - rather, according to the topic or the medium of learning they were developing. For example, there might be a model-making group, a storywriting group, a mathematical investigation group and so on. In this way, primary classrooms often did reflect comprehensive assumptions around trust, co-agency and 'the ethic of everyone' (Swann et al, this volume). This was particularly noticeable within the Inner London Education Authority (ILEA), as it was then called. Secondary classrooms often did not fare so well, despite a rhetoric of comprehensivisation. 
This era was of course before the National Curriculum and its compulsory assessments were introduced in 1988. Despite some excellent intentions of making the curriculum accessible to all children, in practice National Curriculum assessment led to a gradually reformulated perception of children as fitting into categories of 'top', 'middle' or 'bottom' attainment in selected subjects (later narrowed down to maths and writing), as defined by Ofsted inspectors in the 1990s (Hart, 1998). This retrogressive step towards segregation-byattainment was welcomed by both New Labour and the Conservatives, whose policy documents from the 1990s onwards promoted setting and grouping by attainment, in keeping with their purposes of social control and efficiency. This strategy was officially justified on the grounds that such grouping advanced pupils' 'motivation, social skills, independence' as well as academic success in national tests (DfES, 2005, p. 58). Apparently, students in ability groups/sets became 'more engaged in their own learning'. This led to the practice in many primaries whereby children went to separate 'sets' for maths and English, and sat at 'tables' in their main classroom according to their level in National Curriculum maths and/or writing. For example, the 'oblong' table was where all those below the 'norm' sat, the 'circles' table was for those attaining expected levels, while the 'triangles' were exceptional children who were sometimes labelled 'gifted and talented'. Recently, sorting by attainment has even forced its way down into reception classes and infant schools, due to the nature of the government-backed Phonics Check (Bradbury, 2018). Roberts-Holmes (2015) has recently referred to this as the 'datafication' of early years pedagogy; and Ball (2004) earlier coined the phrase 'commodification of the child'. Sorting by attainment has gradually come to be seen as 'natural', as well as the only possible way for teachers to manage all their children (Francis et al, 2016). Many people have (erroneously) come to believe that attainment on tests reflects a child's innate ability or intelligence, and thereby 'attainment' groups are often confused with 'ability' groups.

Research carried out so far agrees on the fact that children in lowest attainment groups actually make less progress in maths and writing than those in other groups, even after controlling for their academic starting points (Wiliam \& Bartholomew, 2004; Higgins et al, 2016). Children grouped as high attainers seem to be the only ones who benefit from attainment segregation, but even these benefits are purely cognitive - that is, these pupils do accumulatively better on tests. What is less clear are the social and affective influences on children who perceive themselves as 'less' (or indeed 'more'). Recent evidence from a very large study led by Becky Francis' team (Francis et al, 2017) suggested that children in the lowest sets developed diminished self-confidence at school (alongside their diminished cognitive progress), while some pupils in 'top' groups came to feel superior to others. What also became clear is that children are placed in lowest attainment groups for reasons beyond attainment but are still stigmatised as 'less than other people'. For example, black pupils are 2.5 times more likely to be placed in lowest sets than their white peers with equivalent attainment scores (Francis et al, 2017), suggesting that black pupils 
are more than twice as likely as their white peers with equivalent attainment scores to perceive themselves as 'less'.

\section{Beyond Grouping: defining children as 'less'}

However, in these studies, the focus has been on grouping strategies. What is studied less is the question of which specific aspects of grouping lead to children feeling 'less'. Is it, for example, the kind of teacher each group gets, the nature of the work given, other pupils' behaviours? Marks $(2013,2016)$ has noted that a classroom where children are perceived to have 'mixed abilities' may perpetuate the same problem as attainment groups - simply because children are perceived in terms of attainment rather than in terms of their overall Life-histories. This scenario is seen in many of the large classes of middle- and low-income countries where lower-attaining pupils tend to be considered not just slow but 'deviant' (Young, 1971; Hargreaves et al, 2018). One obvious problem with grouping by attainment may be that it illustrates in visible, physical structures that pupils have been judged and have been declared as 'less' or 'more'. The segregation is blatantly obvious to pupils, even when we try to disguise it by calling groups 'oblongs' and 'triangles'. But the same dangers can extend to any situation where a pupil is identified by their attainment rather than by their person.

We identified this gaping question in our research: with or without attainment grouping, how are children affected when 'attainment' is used to define the child? Research questions that urgently needed to be addressed included: how does it feel always to be labelled 'low', compared with others who are 'high'? How do young people face the world when they have been subtly - but constantly - told by their system that they are 'less' than others? What actions do these feelings lead to in young people as they grow up? Do children respond with resignation, resilience or resistance? The avenues described below make a start at answering these questions.

\section{Wayne's School Life-History: feeling less of a person}

Wayne was a slight-framed boy in the Year 5 class of a Surrey primary school where I carried out research over six months in 2012-13. He was a chatty child who told me that he liked helping other people. At that time, I visited Wayne's class every week and investigated children's responses to their teacher's feedback (Hargreaves, 2012, 2013, 2014). Every week for six months, I interviewed Wayne and his fellow low attainers, or his peers in higher attainment groups, after observing their (segregated) literacy classes. Wayne is now 18 years old, and I went to talk to him recently about how his school Lifehistory had panned out over the full extent of his schooling. He described how his designation as 'low ability', based on his poor writing skills, had made him feel less of a person since early primary school. 
One lesson I observed when Wayne was nine years old centred around the following poem by Robert Louis Stevenson. I present some detail here to provide an idea of Wayne's approach to learning as a Year 5 boy. The poem started as follows:

From a Railway Carriage

Faster than fairies, faster than witches,

Bridges and houses, hedges and ditches;

And charging along like troops in a battle,

All through the meadows the horses and cattle:

All of the sights of the hill and the plain

Fly as thick as driving rain;

And ever again, in the wink of an eye,

Painted stations whistle by.

The children in Wayne's class were invited to work out, from studying the poem, when the poem might have been written historically. While this task opened up valuable opportunities for collaborative inquiry, it was a difficult task which did not link obviously to the lesson on similes which was the context in which the poem was introduced. However, Wayne's (lowest-attainment) group of six children discussed their ideas of when the poem was written, enjoying an intricate and enthusiastic exploration of train mechanics at different historical periods. After the lesson, I interviewed Wayne, along with his fellow low attainer Laila, and asked them how they had experienced this challenge. The transcription below illustrates how Wayne grappled with the question of when the poem might have been written, and how he indulged competently in his wealth of historical knowledge:

$\mathrm{EH}$ : And you were going to say it was from Victorian times, because $\ldots$ ?

Wayne: Train rides - And I also thought that it was partly from the world war as well.

[It seems that Wayne is toying with two feasible alternatives]

EH: Why is that?

Wayne: Because [the train traveller] could have been going to the countryside.

EH: Oh, an evacuee, from the city [during the war]. That is perfectly possible.

Wayne: Which reminds me that my grand-dad, which is still alive, and my dad's proper dad, he was an evacuee. And my grand-dad who is, you know, sort of a divorce-type of grand-dad, he's dead he died at eighty - but he was a Desert Rat.

[Wayne seems more interested in his own historical knowledge than the answer the teacher had - somewhat unreasonably? - asked for.] Laila: What's a Desert Rat?

EH: Tell Laila what a Desert Rat is. 
Wayne: A Desert Rat is someone - sort of taking different parts of the army - I think, because it's Desert Rat - they sort of took bits of the British Army and bits of the German Army to a desert and fought there.

Laila: I don't understand why the poem could be Victorian...

There's a big space gap. Huge.

EH: There's a big gap between the Victorians and the Second World War.

Wayne: Big, big, big. World war was something like seventy, sixty years ago.

EH: It was the early forties.

Laila: And they didn't really have a lot of paper and pens and stuff... Wayne: But really old paper is just made of strips of tree bark.

Wayne's passion for, and knowledge about, history is evident here, as is his capacity to engage proactively in conversation with an adult. What is less obvious is the pain he was feeling at the time, which he has only recently been able to express. At the time, he did not feel able to tell anyone how anxious he felt. He was unhappy about his relegation to the 'bottom' attainment group and the fact that his peers laughed at him. His small physical stature and his gentle manner seemed to exacerbate the effects. He wrote recently (with help from his mother with the actual writing):

In Year 3, I was kept out of assemblies to practise handwriting skills. That was when I first began to feel 'less' than other people. It made me feel 'less of a person' and it did make it difficult. I found it and still find it extremely difficult to write. All my English lessons have not done anything for me. And being labelled as [low ability] and being clearly given extra help because I couldn't understand is insulting and knocks your confidence - and makes it very easy to give up.

Wayne's curiosity, imagination and drive to construct knowledge were palpable even in Year 5. What Wayne now refers to repeatedly, however, is the fact that when strategies to help him write failed, he was simply urged to try again with even more effort. Other creative ways to deal with his aversion to writing did not seem to be explored; nor were his other strengths and interests, such as history and engineering:

I know they tried to help but it wasn't done right and there was no understanding of why I wasn't getting it. I was just hammered with the same technique that hadn't worked again and again. And surprise, surprise! It didn't work. When I see my awful handwriting today I hate it. It has caused so many issues.

Wayne went on to tell us that at secondary school he was resigned to his place in the 'bottom of the bottom English set', which was so bad it was almost a 
joke. He added, 'We were drilled with the same stuff again and again. It was getting more difficult. None of the fundamentals were sticking in my mind.' However, he was rescued by a teacher 'who came at the whole concept differently, in a more theatrical way. He had us physically acting out scenes to understand them ... [As a result,] most of that [bottom] class passed their English GCSE, me included.' As a consequence, Wayne was accepted at a further education (FE) college at age 16 to study electrical engineering to be an electrician. He commented in interview, with a peaceful smile:

I was able to study something which really interests me and that I am good at and in the process I'm really happy to say that I got one of the top three grades in the whole college for my practical work. And I was told that I have the most imagination of anyone they had ever had. Apart from DT practicals in school and occasionally in maths, this [success during schooling] was a new feeling for me.

(emphasis added)

In other words, from the perspective of contributing in a proactive, original way to his studies, Wayne was a champion. However, from the perspective of fitting the prescribed norm within a system based on traditional values and social efficiency, Wayne continued to be less than other people despite his displays of brilliance. And it was this negative aspect of Wayne's Life-history that dominated his experience. Wayne explained that despite his exceptional achievements during the first year of his sixth-form engineering course, in Year 13, the demand for extensive written assignments obstructed his learning and reminded him of his shame at primary school. He withdrew from college and sought professional help to manage his negative feelings. At the time of writing, Wayne has just returned to college to try to take his final year again. Hopefully his newly found self-awareness and the therapy he received will help him succeed. What is clear, however, is that his label as a 'low attainer' for writing was not helpful to his self-confidence or to his future perception of his identity. He could see that his teachers had tried to help him, but he had found the value system in schooling itself to be destructive. Despite his strengths in a range of other areas, his label as 'low ability' for writing seemed to obscure an alternative identity. Despite the drive to learn and create that I saw in Wayne as a Year 5 pupil, by year 13 resignation seemed to displace his earlier sense of resilience. His agreement, however, to feature in this article indicates his developing awareness of the influences that the schooling system can exert over children. He suggests that he would now like to help other pupils in a similar situation to his: to help them to resist this discourse of test attainment $=$ worth.

\section{The CLIPS Project: investigating pupils' school Life-Histories}

Wayne's story was one of the motivations for the 'Children's Life-histories In Primary Schools' (CLIPS) project which started in April 2018. CLIPS aims to 
explore and extend the idea of children's school Life-histories. Funded by the Leverhulme Trust, the project investigates 24 children's Life-histories in primary schools over five years from Year 3 in primary school to Year 7 in secondary school. The project focuses on 24 children like Wayne who have been labelled 'low attaining' for maths and/or writing, and investigates how they respond to their predicament, whether with resignation, resilience or resistance. It seeks to convey a vivid picture of each of these children's whole primary school Lifehistory, to illustrate the whole child with a whole school life, including and beyond test attainment.

The project includes four schools in the London area, three of which are in pockets of social deprivation. The four schools are very different from each other. In one school, the children are mainly of Bangladeshi origin, in another they are mainly White British, while in the third and fourth, their origin is mainly Black Caribbean and Black African. Many of the children in our sample receive the Pupil Premium, denoting low socio-economic status. We ruled out children with Education Health and Care Plans because Webster and Blatchford's (2013) work explores their experiences in detail already. All 24 children in our sample were chosen because they were attaining least well in maths and/or literacy, as indicated by the school.

We talked first to the 24 pupils when they were completing Year 3 in June 2018. We will now visit each child once every term. We observe and video them in their class for about 20 minutes each visit and then invite them to interview, during which we replay the video clip we have just made of them and ask them to talk through the experience of their time in class. We also encourage open-ended chatting about how the clip relates to their everyday school experiences. We do open-ended activities with the child, to elicit their thoughts about how they experience their designation as 'low' attaining, but without of course referring directly to this at any point. For example, after the first round of interviews, we selected 15 quotes made by a range of pupils during our initial interviews and made each quote into a flash card. In the second round of interviews, we read each quote to the interviewee and asked them to place it under $\mathrm{N}=\mathrm{NO}, \mathrm{Y}=\mathrm{YES}$ or $\mathrm{D}=\mathrm{DON}$ 'T KNOW. For example, one quote was: 'The work in my group is easier.' As they responded, we asked them to explain their choices. Using activities such as these, over five years, we hope to be able to portray vividly the day-to-day and year-on-year experiences (school Life-histories) of individual primary pupils placed in lowest groups. In particular, we will investigate whether/how these children experience a sense of confidence and competence in school learning; the development of their sense of identity and relationships with peers, teachers and family; and their overall attitudes to learning and schooling. By drawing on their accounts and their ideas, we also hope to construct realistic suggestions for practices that fulfil the 'ethic of everybody' and strengthen all children's flourishing and learning. We will ask: could schooling allow all children to embark on a life in which they feel enabled to participate in a valued and 
proactive way, rather than being resigned to the exclusionary hierarchies of the status quo?

\section{First Findings: feeling less of a person}

Wayne's experiences have already been mirrored by children in our CLIPS project. Already, some children have described feeling 'less of a person' when they have had to stay in at break time to finish work that took them longer than others; when they have had a teaching assistant specifically focusing on them rather than other children; when they leave their peers in their normal classroom to go to intervention work; and when they simply perceive that their teacher prefers the 'clever' children. In these cases, we noted the sample children's resignation through silent conformity. In a few instances, we saw buds of resistance - for example, where one child commented that 'schoolwork's not really my thing' so she would rather sleep during class. Many of the children in our CLIPS sample of low attainers have other cultures and countries in their lives, other languages to engage with, unusual experiences to grapple with at home, and a range of unidentified strengths beyond maths and writing at school, which add to the intricacies of their school Life-histories.

We have noticed strikingly, however, that the school environment, the culture and assumptions of school leaders, teachers and teaching assistants, can exacerbate or diminish the children's feelings of worth, depending on how they talk generally about learning and attainment, and depending on how grouping is handled. In some conditions, it seems that grouping by attainment need not carry wholly negative connotations and can at least encourage individuals' resilience, and, at best, encourage social awareness, critique or resistance. This seems to happen when pupils are not only defined by attainment in the adults' minds. In one school in the CLIPS sample, for example, the intervention group (of lowest attainers) is taught by the main class teachers on a rotating basis; children's responses during lessons are constantly built upon and enthusiastically developed; and a range of strategies for learning is used in the intervention group, including engaging learning-games and interesting collaborative work. Children are not constantly praised, but a real interest is taken in whatever they offer. Any mention of children having low attainment is systematically avoided. The children in this group seem least aware of having a low status. We await data over the next five years to explore how these experiences progress.

\section{Conclusion}

Like Mrs Twit, some children who struggle with maths and/or writing start believing over time that they have become 'less' worthy as people, while in reality the competition is not fair - and anyway, it is not a competition! As adults, are these pupils likely to feel a valued part of their society and engage themselves in enhancing it? Will they experience 'parity of participation' (Fraser, 2018)? It seems more likely that they will feel at best resigned and 
marginalised, and at worst resistant and disenfranchised. Some authors claim that, because of the injustice done by stigmatising low attainment, schooling as a system and the people who sustain the system are wielding symbolic violence over the lower-attaining child (Bradbury, 2018; McGillicuddy \& Devine, 2018). It is violence because the child is not aware that this state of affairs is 'constructed' but believes it to be 'natural', and has very little power to change his or her position. The CLIPS project will explore how these beliefs become embedded and how children's resignation to feeling less could be replaced by schooling policies and practices that de-emphasise measurement based on politically inferred needs, and encourage more listening to pupils' own expressed needs and Life-history narratives (see Noddings, 2005). The schooling system has the potential to encourage diverse children to feel equally valued, together with their distinct Life-histories and curriculum strengths, even when these fall outside the 'normal' expectations of global or national forces. But who decides what is 'normal'? Usually those who never themselves experienced being defined as less when they were pupils at school.

\section{Acknowledgements}

Many thanks are due to Wayne for his cooperation, for letting us publish his story and for his feedback. Thanks also to Alex Moore, who kindly engaged me in a fascinating online discussion about the article. Finally, I must thank Denise Buchanan and Laura Quick for all their inspired hard work on the CLIPS project and for reviewing this article so valuably.

\section{References}

Ball, S.J. (2004) Education for Sale: the commodification of everything. King's Annual Education Lecture, University of London.

Bradbury, A. (2018) The Impact of the Phonics Screening Check on Grouping by Ability: a 'necessary evil' amid the policy storm, British Educational Research Journal, 44(4), 539-556. https://doi.org/10.1002/berj.3449

Dahl, R. (1982) The Twits. London: Penguin.

Department for Education and Skills (DfES) (2005) Higher Standards, Better Schools for All: more choice for parents and pupils. London: HMSO.

Francis, B., Archer, L., Hodgen, J., Pepper, D., Taylor, B. \& Travers, M.C. (2016) Exploring the Relative Lack of Impact of Research on 'Ability Grouping' in England: a discourse analytic account, Cambridge Journal of Education, 47(1), 1-17. https://doi.org/10.1080/0305764X.2015.1093095

Francis, B., Archer, L., Hodgen, J., Pepper, D., Taylor, B. \& Travers, M.C. (2017) Attainment Grouping as Self-fulfilling Prophecy?, International Journal of Educational Research, 86, 96-108. https://doi.org/10.1016/j.ijer.2017.09.001

Fraser, N. (2018) Recognition without Ethics? In C. McKinnon \& D. Castiglione (Eds) The Culture of Toleration in Diverse Societies. Manchester: Manchester University Press. https://doi.org/10.7765/9781526137708.00011 
Hargreaves, E. (2012) Teachers' Classroom Feedback: still trying to get it right, Pedagogies, 7(1), 1-15. https://doi.org/10.1080/1554480X.2012.630454

Hargreaves, E. (2013) Inquiring into Children's Experiences of Teacher Feedback: reconceptualising assessment for learning, Oxford Review of Education, 39(2), 229-246. https://doi.org/10.1080/03054985.2013.787922

Hargreaves, E. (2014) The Practice of Promoting Primary Pupils' Autonomy: Examples of Teacher Feedback, Educational Research, 56(3), 295-309. https://doi.org/10.1080/00131881.2014.934554

Hargreaves, E., Elhawary, D. \& Mahgoub, M. (2018) 'The Teacher Who Helps Children Learn Best': affect and authority in the traditional primary classroom, Pedagogy, Culture and Society, 26(1), 1-17. https://doi.org/10.1080/14681366.2017.1314318

Hart, S. (1998) A Sorry Tail: ability, pedagogy and educational reform, British Journal of Educational Studies, 46(2), 153-168. https://doi.org/10.1111/1467-8527.00076

Higgins, S., Katsipataki, M., Villanueva-Aguilera, A.B., et al (2016) The Sutton TrustEducation Endowment Foundation Teaching and Learning Toolkit. London: Education Endowment Foundation (EEF).

Marks, R. (2013) 'The Blue Table Means You Don't Have a Clue': the persistence of fixed-ability thinking and practices in primary mathematics in English schools, FORUM, 55(1), 31-44. https://doi.org/10.2304/forum.2013.55.1.31

Marks, R. (2016) Ability-grouping in Primary Schools: case studies and critical debates. St Albans: Critical Publishing.

McGillicuddy, D. \& Devine, D. (2018) 'Turned Off or 'Ready to Fly': ability grouping as an act of symbolic violence in primary school, Teaching and Teacher Education, 70, 88-99. https://doi.org/10.1016/j.tate.2017.11.008

Moore, A. (2015) Knowledge, Curriculum and Learning: 'what did you learn in school?' In D. Scott \& E. Hargreaves (Eds) The SAGE Handbook of Learning. London: SAGE. https://doi.org/10.4135/9781473915213.n14

Noddings, N. (2005) Identifying and Responding to Needs in Education, Cambridge Journal of Education, 35(2), 147-159. https://doi.org/10.1080/03057640500146757

Reay, D. \& Wiliam, D. (1999) 'I'll Be a Nothing': structure, agency and the construction of identity through assessment, British Educational Research Journal, 24(3), 343-354. https://doi.org/10.1080/0141192990250305

Roberts-Holmes, G. (2015) The 'Datafication' of Early Years Pedagogy: 'if the teaching is good, the data should be good and if there's bad teaching, there is bad data', Journal of Education Policy, 30(3), 302-315. https://doi.org/10.1080/02680939.2014.924561

Sampson, E. (1993) Celebrating the Other: a dialogic account of human nature. Boulder, CO: Westview Press.

Schiro, M. (2013) Introduction to the Curriculum Ideologies. Curriculum Theory: conflicting visions and enduring concerns, 2nd edn. Thousand Oaks, CA: SAGE.

Unger, R. (2011) The Future of the Left, The European, 24 October.

Webster, R. \& Blatchford, P. (2013) The Educational Experiences of Pupils with a Statement for Special Educational Needs in Mainstream Primary Schools: results 
from a systematic observation study, European Journal of Special Needs Education, 28(4), 463-479. https://doi.org/10.1080/08856257.2013.820459

Wiliam, D. and Bartholomew, H. (2004) 'It's Not Which School but Which Set You're in That Matters': the influence of ability grouping practices on student progress in mathematics, British Educational Research Journal, 30(2), 279-293. https://doi.org/10.1080/0141192042000195245

Young, M. (1971) Knowledge and Control. London: Collier Macmillan.

ELEANORE HARGREAVES is Reader in Learning and Pedagogy at the UCL Institute of Education in London. She is author of Children's Experiences of Classrooms (2017). The book reflects her interest and research into how children experience and make sense of schooling, including how they experience and/or negotiate a teacher's authority, how and whether they draw on their own agency through self-directing their learning, how they respond to teachers' feedback and what happens to them and to their learning when they are grouped by 'ability'. She explores the role of inequality in schooling and learning and has worked extensively in low- and middle-income countries' schools, especially in the Middle East and North Africa. Since April 2018, she has been leading a Leverhulme-funded longitudinal research project investigating 'Children's Life-histories In Primary Schools' (CLIPS), emphasising the role played by grouping and labelling by attainment. Correspondence: e.hargreaves@ucl.ac.uk 